\title{
Os Odontoideum (00): A Rare Cause of Cervical Myelopathy- Reports of two cases
}

\author{
GOPEN KUMAR KUNDU, ${ }^{1}$ A.B.M MUKIB,${ }^{2}$ KRISHNA MOHON PODDAR ${ }^{2}$, LAILAARJEUMAN², \\ SHAHEEN AKHTER ${ }^{3}$
}

\begin{abstract}
Summary
Os odontoideum (OO) is a rare condition defined radiographically as an oval or round-shaped ossicle of variable size with smooth circumferential cortical margins representing the odontoid process that has no continuity with the body of second cervical vertebra (C2). Since the upper cervical spinal region is complex from anatomical point of view and has many vital structures passing in close relation to each other it is important to review this topic. If a person suffers from hyper mobile dens due to insuffiency of its ligamentous complex, it may cause translation of the atlas on the axis and may compress the cervical cord or vertebral arteries. However, patients with this condition may be asymptomatic or may be symptomatic of a variety of neurological deficits and vascular dysfunctions. There are cases where patients suffering from Os odontoideum became quadriplegic after a minor trauma. The treatment of both the asymptomatic and symptomatic characteristics of this condition has undergone changes over the past few decades. In our paper we present two cases who presented as spastic quadriplegia, then was diagnosed as Os odontoideum (OO) and treated.
\end{abstract}

\section{Introduction:}

Os odontoideum $(\mathrm{OO})$ is an uncommon craniovertebral junction (CVJ) abnormality that exists as a separate ossicle apart from a hypoplastic dens. OO has been described by some other name as Cleft Dens Disease, Incomplete Dens Disease and Independent Dens Fragment Disease. There is controversy regarding its pathogenesis - but its cause is presumed to be both congenital and traumatic. Some other congenital anomalies related to the odontoid process have been defined in literature as aplasia, hypoplasia, duplication, condylustertius, osterminale (osavis). ${ }^{1}$

The word $\mathrm{OO}$ has a Latin origin derived from os (bone) and odontoideum (tooth-like).As the size of the ossicle is variable, it has a smooth surface, therefore, the cause of this condition is still controversial - presumed to be both congenital and

1. Associate professor, Department of Paediatric Neurology, IPNA, BSMMU

2. Student, Paediatric Neurology and Development, BSMMU

3. Professor and Director IPNA, BSMMU

Correspondence: Dr. Gopen Kumar Kundu, Associate professor, Department of Paediatric Neurology, IPNA, BSMMU. Cell no01718590768, Email-gopen.kundu@gmail.com

Received: 4/03/2020

Accepted: $3 / 07 / 2020$ traumatic. ${ }^{2} \mathrm{OO}$ is more prevalent among males and is usually seen in the second and third decades of life. It is uncommon in middle age and is rare in the elderly. ${ }^{3}$ Among the main 2 types - the orthotopic type where os is in its normal position thus, available for free movement with the anterior arch of the atlas. However, in dystopic type where os lies close to the base of the clivus or is fused to the basion thus, available for movement with the clivus. ${ }^{4}$

This lesion usually presents clinically in pediatric population, moreover, most authors today believe it might represent an unrecognized fracture or damage to the epiphyseal plate during the first few years of life. ${ }^{5}$ Some believe that it may represent a congenital anomaly instead of occult trauma. ${ }^{6}$ The clinical presentation is a wide range starting from complete asymptomatic to devastating neurological injury. Some might express symptoms secondary to vertebral artery compression. Here we described 2 paediatric cases presented with progressive quadriparesis and finally diagnosed as Os Odontoideum (OO).

\section{Case - 1}

A 3.5 years old female child of non consanguineous parents presented with difficulties in walking for last 
8 months which was gradually progressive. She also complained of neck pain and difficulty in holding objects for last 8 months. On further query mother gave history of fall from height before this illness. She has no history of headache, fever, convulsion, weight loss, bowel bladder incontinence, contact with tuberculous patient. On examination, patient was anthropometrically well thriving. Higher psychic function was normal, There was signs of upper motor neuron lesion in all four limbs, gait was spastic but sensory functions and cerebellar functions were intact. Provisionaly myelopathy was considered due to trauma or tumour or tuberculosis. Complete blood count, chest X-ray and MT was not suggestive for TB, X-ray cervical spine showed no abnormality (Fig1). MRI of spine showed mild atlanto axial subluxation. The spinal cord showed focal T2 hyperintensity at $\mathrm{C} 2$ level (Fig -2$)$.

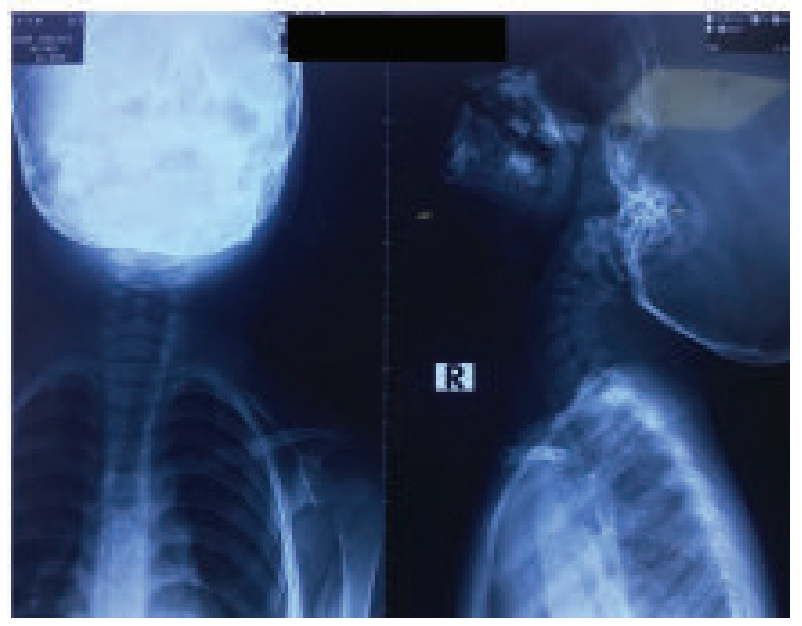

Fig.-1: $X-R$ neck $A P$ and Lateral view

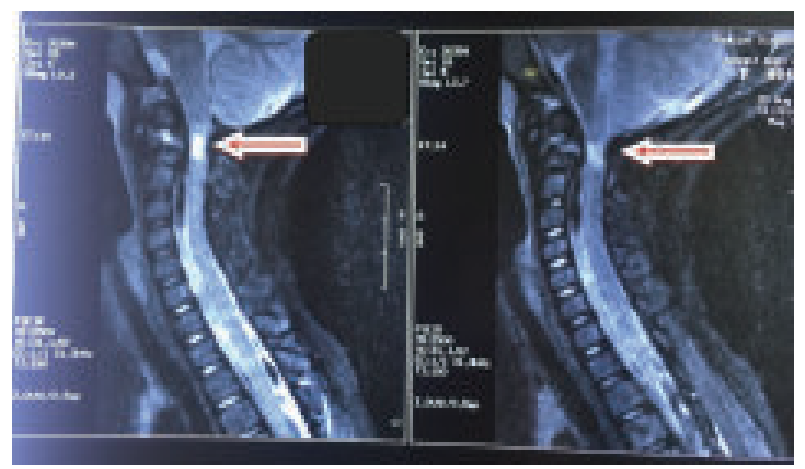

Fig.-2: MRI (T2WI) of Cervical spine

Contrast enhanced CT scan of cervical spine showed altered cervical lordosis and old non united fracture odontoid process and body of C2 vertebra with anterior angulation of odontoid process (Fig - 3). So our final diagnosis was Chronic Compressive Cervical myelopathy at C2 level due to OS odontoideum (OO).

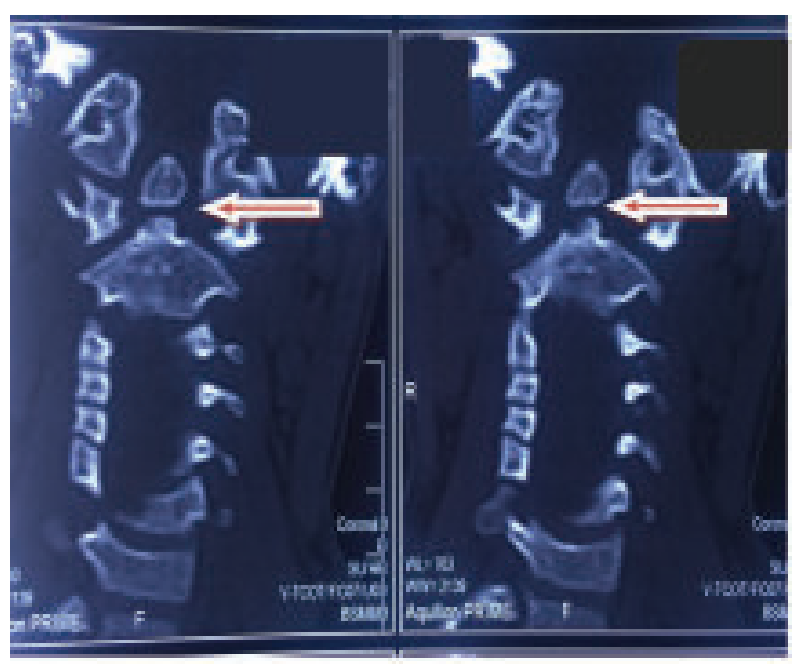

Fig.-3: CECT of cervical spine

\section{Case -2}

A 5 years old immunized girl presented with neck pain for 2 years. The pain was initially in her right upper arm but progressively involved all four limbs. Pain was not radiating in nature, not associated with headache or vomiting but was associated with numbness. She also developed difficulty in walking for 5 months. There was no $\mathrm{H} / \mathrm{O}$ any injury in the neck, fever, weight loss, breathing difficulty or any bowel bladder dysfunction. She was developmentally age appropriate before the illness. On examination, she was well thriving, conscious, back and spine was normal. Cranial nerves were intact. Motor system examination of all 4 limbs showed there was no visible muscle wasting. Tone was normal, power $4 / 5$, deep tendon reflexes were exaggerated in all four limbs, plantar was bilaterally extensor. All modalities of sensation was intact. Gait was spastic. As there was features of cervical lesion we investigatedthe child by doing an MRI of cervical spine which showed-hyper intense signal change within the spinal cord extending from $\mathrm{C} 1-\mathrm{C} 4$ vertebral level and old non united odontoid process of $\mathrm{C} 2$ vertebra in T2WI (Fig-4), suggestive of cervical myelopathy due to Os odontodium. 


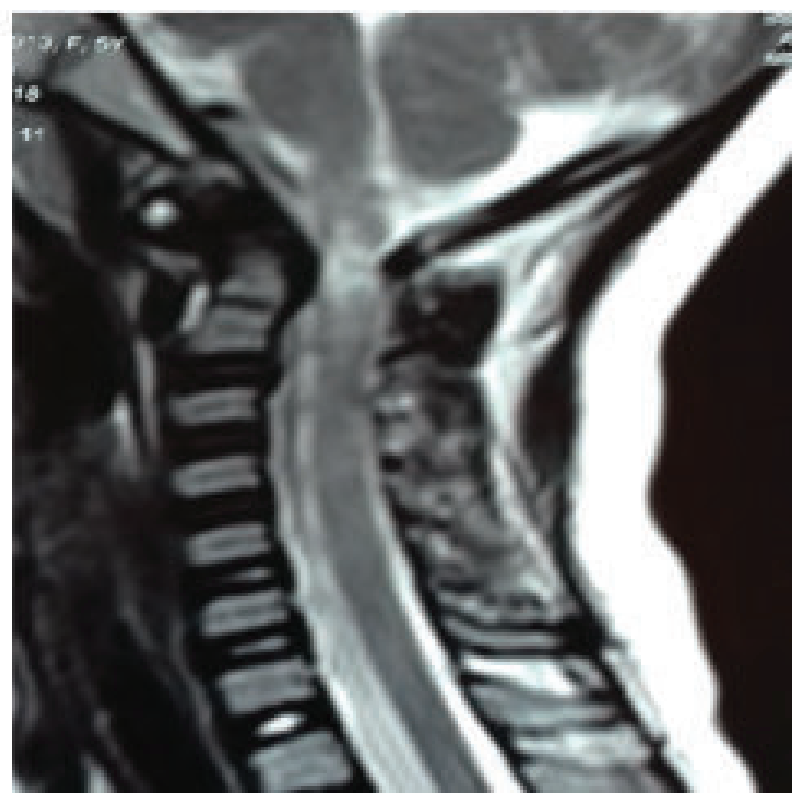

Fig.-4: MRI showing cervical myelopathy

\section{Discussion:}

Os odontoideum (OO) is a rare condition defined radiographically as an oval or round-shaped ossicle of variable size with smooth circumferential cortical margins representing the odontoid process that has no continuity with the body of $\mathrm{C} 2 .^{7}$ The hypoplasia of the odontoid process associated with the oval ossicle, widely separated from the body of the axis, is termed as OO. In our $1^{\text {st }}$ case there was a trivial history of trauma but in the second case there was no history of minor trauma - presumed to be congenital in origin. $\mathrm{OO}$ is more prevalent among males and is usually seen in the second and third decades of life. ${ }^{2}$ But both of our cases were female and presented in $1^{\text {st }}$ decade. The embryology, growth, and development of the odontoid process is complex. The centrum of the fourth occipital sclerotome forms the apical cap of the dens and the remaining portion of the odontoid process originates from the mesenchyme of the sclerotome of the first cervical vertebrae. The dens reunites to the body, begins in the $4^{\text {th }}$ year of life, although it might be delayed until age of 12 years. $^{8}$ Many patients with $\mathrm{OO}$ might remain asymptomatic throughout their life or many become symptomatic as early as in childhood. Therefore, it is classified into two categories of patients: symptomatic and asymptomatic. ${ }^{3}$

As the spinal canal is relatively wide at the C1-2 level, symptoms are not seen in this area. ${ }^{9}$ Patients with the asymptomatic condition have been doing well over a number of years without proper treatment. ${ }^{2,8}$ Cases of sudden spinal cord injury in patients with OO after minor trauma have been reported. ${ }^{10}$ In symptomatic cases, neck and shoulder pain is most often seen. Less frequently reported symptoms are headache, torticollis, thinness and weakness. The most serious complication of $\mathrm{C} 1-\mathrm{C} 2$ instability develops because of spinal cord compression or obstruction of the vertebral artery. A dystopic $\mathrm{OO}$ is mostly diagnosed among young adults. ${ }^{4,8}$ There is often a history of trivial, significant remote or recent trauma, which often makes it difficult to distinguish between an odontoid fracture and a congenitally separated odontoid. In both of our indexed cases there was neck pain, pain in limbs during walking and progressive weakness and paresthesia in all four limbs and signs of UMNL was present - suggestive of cord compression. There was a history of trivial trauma (in case 1) which make the diagnosis difficult.

Plain X-rays and CT may observe OO with intact cortical margin above the axis. The smooth, wellcorticated, sclerotic margins and round or oval shape asobserved can help distinguish this pathological condition from non-corticated dens fractures with irregular margins of an acute type II odontoid fracture. However, a high-resolution multiplanar computed tomography (CT) scan might be necessary to observe the detailed anatomy of $\mathrm{OO}$ and any associated cervical or skull base anomalies for planning surgical action. ${ }^{2}$ An MRI study should also be done to evaluate any intrinsic spinal cord signal changes (hypointense lesion in T1-weighted images and hyperintense signal intensity lesion in T2weighted MRI ) known as myelopathy as well as a non united odontoid process with body of C2. MRI also helps to distinguish other pathology like cervical spondylosis or cervical spondylotic myelopathy, a retro-odontoid synovial cyst (uniform low intensity on T1-weighted images and uniform high signal intensity on T2-weighted images).

Hypertrophy and sclerosis of the anterior tubercle of atlas are used to differentiate $\mathrm{OO}$ from an acute dens fracture. If $\mathrm{OO}$ is seen together with chromosomal and genetic anomalies such as Down's syndrome and multiple epiphyseal dysplasia, it supports that it is congenital. ${ }^{2,11}$

Observations are suffice in asymptomatic subjects with a stable spine, no treatment for radiographic 
stable $\mathrm{OO}$ in asymptomatic subjects. ${ }^{7}$ Sudden death or significant neurological morbidity when subjected to minor trauma, is more commonly observed in children and young adults who are subject to highenergy traumas. So parents should be informed about the possibility of sudden displacement of the dens due to traumas inherently associated with some sports. Therefore, observation and periodic flexionextension cervical radiographs are recommended to be recorded at an annual interval. In symptomatic cases the management of atlantoaxial instability due to $\mathrm{OO}$ in children fixation surgery is needed (transarticular C1-C2 fixation technique) though it is a challenging issue due to the smaller size of the spine. $^{3}$

Poor outcome are associated with chronic patients who are in a poor preoperative grade. Concomitant gliosis of the nuclei at the cervicomedullary junction, and demyelination of long tracts at this region due to repeated trauma and hypoxia due to venous stasis, have been implicated as the probable causes of poor outcome after surgery. ${ }^{3}$

\section{Conclusion:}

Os odontoideum $(\mathrm{OO})$ is not a very uncommon condition. Its common presentation is neck pain but may present with quadriparesis. Early diagnosis is essential to reduce mortality and morbidity.

\section{References}

1. Kaya AR, Turkmenoglu O, H Cavusoglu H, Kahyaoglu $O$, Aydin Y.Osodontoideum: a case report.Turk Neurosurg. 2005;15:157-61.

2. Bahadir C, Yaman V, Taraktas A. Cervical myelopathy caused by osodonteideum: case report. Turkish Journal of Rheumatology.2009;1:53-6.

3. Rahimizadeh A, Rahimizadeh A. Os odontoideum: a review article. Orthop Res Traumatol. 2016;1: 33-55.

4. Fielding J, Hensinger R. Hawkins Pa1. Os odontoideum. J Bone Joint Surg Am980;62:376-83.

5. Brecknell J, Malham G. Os odontoideum: report of three cases. Journal of Clinical Neuroscience. 2008;15:295-301.

6. Arvin B, Fournier-Gosselin M-P, Fehlings MG. Os odontoideum: etiology and surgical management. Neurosurgery. 2010;66:A22-A31.

7. Perrini $P$, Montemurro N, lannelli A. The Contribution of Carlo Giacomini (1840-1898) The Limbus Giacomini and Beyond. Neurosurgery. 2012;72: 475-82.

8. Spierings E, Braakman R. The management of os odontoideum. Analysis of 37 cases. The Journal of Bone and Joint Surgery. British volume1982;64:422-28.

9. Henderson S, Henderson D. Os odontoideum with associated multidirectional atlantoaxial instability: imaging and clinical considerations. J can chiropr Assoc. 2006;50:111-17

10. Menezes AH. Pathogenesis, dynamics, and management of os odontoideum. Neurosurgical focus.1999 Jun 15;6(6):e2. PMID: 16972748.

11. Yücesoy $K$, Yüksel $M$, Kalemci $O$, Yüksel $K Z$. Os Odontoideumlu Bir Olgunun Radyolojik Görüntüleme Bulgularý ve Ayýrýcý Tanýsý: Olgu Sunumu.J Nervous Sys Surgery 2010; 3(2):84-88 